\title{
Vaccination and Malaria Prevention among International Travelers Departing from Athens International Airport to African Destinations
}

\author{
Androula Pavli, Athina Spilioti, Paraskevi Smeti, Stavros Patrinos, and Helena C. Maltezou \\ Department for Interventions in Health Care Facilities, Hellenic Center for Disease Control and Prevention, \\ 3-5 Agrafon Street, 15123 Athens, Greece \\ Correspondence should be addressed to Helena C. Maltezou; helen-maltezou@ath.forthnet.gr
}

Received 9 December 2013; Revised 9 January 2014; Accepted 22 January 2014; Published 2 March 2014

Academic Editor: Sukla Biswas

Copyright (C) 2014 Androula Pavli et al. This is an open access article distributed under the Creative Commons Attribution License, which permits unrestricted use, distribution, and reproduction in any medium, provided the original work is properly cited.

\begin{abstract}
Background. International travel to Africa has grown dramatically over the last decade along with an increasing need to understand the health issues for travelers. The current survey aimed to assess vaccination and malaria prevention of travelers visiting Africa. Methods. A questionnaire-based survey was conducted from of November 1, 2011 to of April 30, 2013 at Athens International Airport. Results. A total of 360 travelers were studied; $68 \%$ were men. Their mean age was 39.9 years. Previous travel to tropical countries was reported by $71.9 \%$ of them. Most frequent destination was sub-Saharan Africa (60\%). Most of them traveled for $\geq 1$ month (62\%). The main reason for travel was work (39.7\%). Only $47 \%$ sought pretravel consultation. Hepatitis A, typhoid, and meningococcal vaccines were administered to $49.8 \%, 28 \%$, and $26.6 \%$, respectively, and malaria chemoprophylaxis to $66.8 \%$ of those who visited sub-Saharan Africa. A history of previous travel to a tropical country, elementary level of education, and traveling for visiting friends and relatives, and for short duration were significant determinants for not pursuing pretravel consultation. Conclusions. The current survey revealed important inadequacies in vaccine and malaria prophylaxis of travelers departing to Africa. Educational tools should be developed in order to improve awareness of travelers to risk destinations.
\end{abstract}

\section{Introduction}

International travel has increased in the last six decades worldwide with the highest increase noted in tropical and subtropical areas. International tourist arrivals grew by $4 \%$ in 2012 and for the first time in history exceeded one billion. In 2012, a 6\% increase was recorded for Africa, equivalent to 3 million more travelers, reaching 50 million for the first time ever [1]. Travelers to tropical and subtropical countries can be exposed to various infectious diseases and may facilitate their importation into countries where these diseases are not endemic $[2,3]$. Approximately $8 \%$ of travelers to developing countries require medical care during or after travel; the main diagnoses include acute diarrhoea, malaria, and dengue fever [3]. Sub-Saharan Africa was one of the most common regions (26.7\%) where illnesses were acquired, as recorded by the GeoSentinel surveillance network [4].

The importation of vaccine-preventable diseases has been recognized as an important travel-related problem [5]. Vaccine preventable diseases (VPDs) accounted for $1.5 \%$ of ill returned travelers, with enteric fever, acute viral hepatitis, and influenza as the most common diagnoses [5]. Malaria is one of the most important travel associated diseases due to its widespread geographic distribution and its potential fatal outcome if untreated, especially in nonimmune individuals. Malaria diagnosis accounted for $29 \%$ of those with fever and disproportionally in travelers returning from Africa [4]; according to the global data base, the majority of the infections were acquired in sub-Saharan Africa and $60 \%$ of them were due to Plasmodium falciparum [6].

As a result of growing international travel, health consultants are increasingly likely to be consulted for advice before travel or by ill returned travelers. Previous studies have revealed that a large proportion of travelers do not seek pretravel advice [7-12]. The current study aimed to assess pretravel consultation seeking practices and provision of vaccinations and malaria prophylaxis among international travelers departing from Athens International Airport and visiting African countries. 


\section{Materials and Methods}

A prospective questionnaire-based study was conducted from November 1, 2011 to April 30, 2013. Data collection was carried out 2 days weekly. Travelers leaving from the departure gates of Athens International Airport were invited to participate in the survey. Selection criteria were being a Greek resident, $\geq 19$ years old, and traveling to Africa. Travelers participated on a voluntary basis; no incentive was provided. Permission was given by the International airport Authority, the airlines flying to the above destinations, and the Hellenic Center for Disease Control and Prevention (HCDCP).

Data were collected using a standardized anonymous questionnaire specifically designed in Greek language. It was administered by 2 trained interviewers and lasted about 10 minutes. Data included information about demographic and travel characteristics, and pretravel consultation (vaccination, malaria prophylaxis, general preventive measures, and source of pretravel consultation). Up to 5 travelers were interviewed per day, depending on the selection criteria.

High risk areas and those with moderate-high prevalence of malaria were defined according to published sources [6, 13]. The definition of high risk travelers with regard to exposure to malaria in endemic areas was based also on travel (area and place of stay, duration and purpose of travel, and activities) and travelers' characteristics (age, behaviour, and medical history). Adequate vaccine and malaria prophylaxis is considered according to the national Hellenic Centre for Disease Control and Prevention guidelines, which are in accordance with the World Health Organization and US Centers for Disease Control and Prevention guidelines [14-16]. Urban accommodation was defined as cities with population of 5,000 people or more, whereas rural accommodation was defined as villages with up to population of 5,000 or staying in the countryside (Hellenic Statistics Authority: personal communication). Short-term travel was defined as a trip of $<1$ month duration, while long-term travel was defined as a trip of $\geq 1$ month. An organized trip was defined as a guided, package trip, mainly to popular tourist destinations. Outdoor activities include adventure sport, backpacking, hiking, and remote expedition. Travelers VFRs were classified as those immigrants to Greece who return to their homeland, a lower income country, to visit friends or relatives according to a definition outlined by the US Centers for Disease Control and Prevention (CDC) [17].

Chi-squared test and Fisher's exact test were used for comparison between categorical variables. The standard multiple logistic regression was conducted (if $P$ value $<$ 0.15 in univariate analysis) to examine the relation between pretravel preparation and independent factors. Multivariate analysis was used in order to identify factors influencing the attitude to pretravel consultation. Odds ratios (ORs) and their 95\% confidence intervals (CIs) were calculated. $P$ values of 0.05 or less were considered statistically significant. Unanswered items were excluded from the analysis. Analysis was performed using STATA v12.1 software.

\section{Results}

A total of 360 travelers participated in the survey $(98 \%$ participation rate); $60 \%, 35 \%$, and $5 \%$ were traveling to subSaharan Africa, North Africa, and Southern Africa region (based on United Nations' classification), respectively; more than one quarter of them visited for the first time a tropical or subtropical country. The number of travelers to African destinations was approximately stable throughout the study period. The five most common African countries were Egypt (35\%), Ethiopia (13.3\%), Kenya (8.3\%), Ghana, and Nigeria (7.2\% each). Sixty-two percent of travelers visited malaria endemic areas.

Table 1 describes travelers' and travel characteristics. The majority of international travelers were male, of Greek nationality and with tertiary education. One-third of the travelers were foreign born; $56.1 \%$ of them were born in North Africa (mainly in Egypt) and Ethiopia. Outdoor activities and contact with animals were reported by 67 (18.6\%) and 15 (4.2\%), respectively. Those traveling for leisure and VFRs were more likely to be involved in outdoor activities than those traveling for work $(31.9 \%$ and $29.9 \%$, resp., versus 15.4\%) $(P$ value $<0.001)$

Half of all travelers reported having sought pretravel consultation and most of them sought consultation 15-28 days prior to departure (Table 1). The majority of those who pursued health information $(61.5 \%)$ had a history of previous travel to a tropical country $(P$ value $<0.001)$, traveled to sub-Saharan Africa $(89.4 \%)(P$ value $<0.001)$, and stayed in local houses $(56.1 \%)(P$ value $<0.001)$. Of those traveling for business, leisure, and VFRs, $60 \%, 24.4 \%$, and $12.2 \%$ sought pretravel advice, respectively $(P$ value $<0.001)$.

Vaccination (previous vaccination or vaccination prior to the current trip) according to destination is described in Table 2. A total of 572 vaccines were administered to 136 (37.8\%) of travelers (mean number of vaccines: 4.2 , range: $1-$ $14) ; 122(89.7 \%)$ and $14(10.3 \%)$ received travel and routine vaccines, respectively. The vaccines most commonly administered were hepatitis A, yellow fever, and tetanus/diphtheria vaccines. More than $90 \%$ of travelers visited areas of high endemicity for hepatitis A, and nearly $80 \%$ of them areas endemic for typhoid fever. Hepatitis A and typhoid vaccination rates were lower than expected (60\% and 55\%, resp.). All travelers who received meningococcal vaccine traveled to sub-Saharan Africa (16.1\%); retrospective analysis of data based on travelers' and travel characteristics, revealed that this rate was lower as expected by $25 \%$. Similarly, all of those to whom yellow fever vaccine was administered traveled to sub-Saharan Africa; this rate was considered slightly lower than expected (10\%). Rabies vaccine was administered to only $1.9 \%$ of all travelers and only to travelers visiting sub-Saharan Africa.

Vaccination in relation to purpose of travel revealed that more of those who traveled for recreation received hepatitis A vaccine than business travelers, VFRs, and tourists $(54.2 \%$ versus $47.5 \%$ and $5.8 \%$, resp.) ( $P$ value $<0.001)$, whereas more business travelers were administered typhoid fever vaccine than VFRs and tourists (40.6\% versus $2.2 \%, 0 \%$, resp.) $(P$ value $<0.001)$. Similarly, more business travelers received 
TABLE 1: Characteristics of travelers to African countries and pretravel health advice $(N=360)$.

\begin{tabular}{|c|c|}
\hline & $N(\%)$ \\
\hline \multicolumn{2}{|l|}{ Gender } \\
\hline Male & $245(68.1)$ \\
\hline \multicolumn{2}{|l|}{ Age (years) } \\
\hline $19-34$ & $106(29.4)$ \\
\hline $35-49$ & $215(59.7)$ \\
\hline $50-64$ & $33(9.2)$ \\
\hline$\geq 65$ & $6(1.7)$ \\
\hline \multicolumn{2}{|l|}{ Education } \\
\hline University/tertiary & $235(65.3)$ \\
\hline Secondary school & $51(14.2)$ \\
\hline Elementary school & $67(18.6)$ \\
\hline \multicolumn{2}{|l|}{ Nationality } \\
\hline Greek & $230(63.9)$ \\
\hline Other & $130(36.1)$ \\
\hline \multicolumn{2}{|l|}{ Employment } \\
\hline Yes & $314(87.2)$ \\
\hline \multicolumn{2}{|c|}{ Previous travel to tropical or subtropical country } \\
\hline Yes & $259(71.9)$ \\
\hline \multicolumn{2}{|l|}{ Traveled with } \\
\hline Alone & $200(55.6)$ \\
\hline Friends and relatives & $61(16.9)$ \\
\hline Husband/wife & $46(12.8)$ \\
\hline Group & $24(6.7)$ \\
\hline Children & $28(7.8)$ \\
\hline Other & $1(0.3)$ \\
\hline \multicolumn{2}{|l|}{ Duration of travel } \\
\hline$<1$ month & $137(38.1)$ \\
\hline 1-3 months & $117(32.5)$ \\
\hline 3-6 months & 49 (13.6) \\
\hline$>6$ months & $57(15.8)$ \\
\hline \multicolumn{2}{|l|}{ Purpose } \\
\hline Recreation & $72(20)$ \\
\hline Work & $143(39.7)$ \\
\hline VFR's & $137(38.1)$ \\
\hline Religious reasons & $1(0.3)$ \\
\hline Education & $5(1.4)$ \\
\hline Other & $2(0.6)$ \\
\hline \multicolumn{2}{|l|}{ Place of stay } \\
\hline Local residence & $230(63.9)$ \\
\hline Hotel & $114(31.7)$ \\
\hline Ship & $9(2.5)$ \\
\hline Camping & $6(1.7)$ \\
\hline Other & $1(0.3)$ \\
\hline \multicolumn{2}{|l|}{ Area of stay } \\
\hline Urban & $233(64.7)$ \\
\hline Urban and rural & $89(24.7)$ \\
\hline Rural & $35(9.7)$ \\
\hline
\end{tabular}

TABLE 1: Continued.

\begin{tabular}{lc}
\hline & $N(\%)$ \\
\hline $\begin{array}{l}\text { Time in which pretravel health advice was } \\
\text { sought before the journey }(\mathrm{d})\end{array}$ & \\
$\quad$ Yes & $180(50)$ \\
$\leq 7$ & $11(3.1)$ \\
$8-14$ & $62(17.2)$ \\
$15-28$ & $66(18.3)$ \\
$\geq 28$ & $41(11.4)$ \\
Sources of pretravel advice & \\
Yes & $170(47.2)$ \\
Public Health Department & $153(42.5)$ \\
HCDCP & $103(28.6)$ \\
Internet & $34(9.4)$ \\
Primary Care Doctor & $31(8.6)$ \\
Other & $4(1.1)$ \\
Hospital & $0(0)$ \\
\hline
\end{tabular}

meningococcal vaccine than tourists and VFRs (32.2\% versus $11.1 \%$ and $1.5 \%$, resp.) $(P$ value $<0.001)$. Yellow fever was delivered to $44.8 \%$ of business travelers, $37.5 \%$ of tourists, and $6.6 \%$ of VFRs $(P$ value $<0.001)$.

The association between tetanus/diphtheria, poliomyelitis, hepatitis B, hepatitis A, typhoid, yellow fever and meningococcal vaccination, and destination and more specifically with sub-Saharan Africa was statistically significant $(P$ value $<0.001)$.

Malaria prophylaxis according to destination is shown on Table 3. A total of 146 travelers were prescribed chemoprophylaxis. Mefloquine was the most commonly prescribed antimalarial (54.7\%). Nearly 22\% (77) of travelers who visited malaria endemic areas did not receive any antimalarials.

There was a statistically significant association between malaria chemoprophylaxis, general advice, and destination. Most of those who traveled to sub-Saharan Africa (66.8\%) were prescribed chemoprophylaxis than to other destinations ( $P$ value $<0.001$ ); $55.2 \%$ and $44 \%$ of them received mefloquine and atovaquone/proguanil, respectively. In terms of purpose of travel, more business travelers $(66.9 \%)$ received antimalarials than tourists $(51.4 \%)$ and VFRs $(6.6 \%)(P$ value $<0.001)$.

Table 4 describes travelers' and travel characteristics in relation to purpose of travel. The association of purpose of travel (recreation, work, and VFRs) with age, gender, education, employment, destination, place and area of stay, and duration of travel was statistically significant $(P$ value $<$ 0.001).

Multivariate analysis was used in order to investigate the association of several factors with failing to pursue pretravel health consultation among travelers to African destinations. Having a history of previous travel to a tropical country, having an elementary or secondary level of education, traveling for visiting friends and relatives, $k$ traveling for short duration and traveling with someone were significant determinants for not pursuing pretravel consultation (Table 5). 
TABLE 2: Vaccine prophylaxis according to destination* .

\begin{tabular}{|c|c|c|c|}
\hline & \multicolumn{3}{|c|}{$N(\%)$} \\
\hline & Sub-Saharan Africa & North Africa & South Africa \\
\hline & $N=216$ & $N=126$ & $N=18$ \\
\hline \multicolumn{4}{|l|}{ Routine vaccines $^{* *}$} \\
\hline Hepatitis A & $108(49.8)$ & $8(6.4)$ & $2(11.1)$ \\
\hline Tetanus/diphtheria & $95(43.8)$ & $6(4.8)$ & $2(11.1)$ \\
\hline Hepatitis B & $36(16.3)$ & $2(1.6)$ & $0(0)$ \\
\hline Poliomyelitis & $39(18.1)$ & $0(0)$ & $0(0)$ \\
\hline Measles, Mumps, Rubella & $13(6.1)$ & $0(0)$ & $0(0)$ \\
\hline Influenza & $7(3.3)$ & $1(0.8)$ & $0(0)$ \\
\hline Pneumococcal & $5(2.3)$ & $0(0)$ & $0(0)$ \\
\hline \multicolumn{4}{|l|}{ Travel vaccines } \\
\hline Typhoid fever & $61(28)$ & $2(1.6)$ & $0(0)$ \\
\hline Cholera & $6(2.8)$ & $0(0)$ & $0(0)$ \\
\hline Yellow fever & $104(48)$ & $0(0)$ & $0(0)$ \\
\hline Meningococcal (A, C, W135, Y) & $58(26.6)$ & $0(0)$ & $0(0)$ \\
\hline Rabies & $7(3.3)$ & $0(0)$ & $0(0)$ \\
\hline Tick-born ${ }^{* * *}$ encephalitis & $5(2.3)$ & $0(0)$ & $0(0)$ \\
\hline Japanese encephalitis ${ }^{* * *}$ & $5(2.3)$ & $0(0)$ & $0(0)$ \\
\hline
\end{tabular}

${ }^{*}$ Vaccination was administered to 136 travelers (37.8\%).

${ }^{* *}$ In accordance with the National Vaccination Program of Greece.

${ }^{* * *}$ Recent vaccination for a trip to tick-born encephalitis endemic countries.

**** It was administered to travelers with South East Asia as a second destination.

TABLE 3: Malaria chemoprophylaxis according to destination*

\begin{tabular}{lcccc}
\hline & Mefloquine & $\begin{array}{c}\text { Atovaquone/ } \\
\text { proguanil }\end{array}$ & Doxycycline & Total \\
\hline North Africa & $0(0)$ & $0(0)$ & $0(0)$ & 126 \\
Sub-Saharan Africa & $79(36.7)$ & $63(29.3)$ & $1(0.5)$ & 216 \\
South Africa & $1(0)$ & $2(11.8)$ & $0(0)$ & 18 \\
Total & $\mathbf{8 0 ( 2 2 . 2 )}$ & $\mathbf{6 5 ( 1 8 )}$ & $\mathbf{1 ( 0 . 3 )}$ & $\mathbf{3 6 0}$ \\
\hline
\end{tabular}

${ }^{*}$ Malaria chemoprophylaxis was prescribed to 146 travelers (40.6\%).

\section{Discussion}

During the period 2009-2010 nearly 34,000 travelers from Greece visited countries of Africa [18]. Most of these destinations are endemic to a variety of infectious diseases which may cause considerable morbidity and mortality. The aim of the current survey is to study the profile of Greek travelers visiting Africa, and their pretravel health seeking practices including vaccine and malaria prevention.

The profile of the participants in the present study revealed that more than two-thirds of international travelers were travelers with employment and a history of previous travel to tropical and subtropical countries and with tertiary level of education. Travelers with this profile are expected to be more receptive to awareness about health prevention. However, the overall level of practice regarding vaccinations and malaria chemoprophylaxis was low.

In regard to the demographics of the study population the results were comparable to those of other similar studies; most of the travelers were men and young or middle aged
[7-12]. The percentage of those traveling alone was higher compared to that of other studies $[8,10]$. Nearly thirty percent traveled to tropical and subtropical countries for the first time. Similar rate was noted in a Spanish study [8].

In regard to purpose of travel, the results of the present survey showed that the number of those traveling for the purpose of work or VFRs was higher, whereas the rate of those traveling for leisure was lower compared to the results of other studies [7, 8, 10, 11]. VFRs traveled predominantly to North Africa, which may reflect the composition of the African VFR population in Greece, and those who traveled for recreation and work visited mainly sub-Saharan Africa. The majority of business travelers stayed for long period of time, which explains the fact that most of them stayed in local houses. Compared to a previous Greek study the current survey shows a changing profile of Greek travelers to developing countries [19]; this may be due to the influence of economic crisis in Greece which is reflected on immigration and international travel.

In the current study, less than half of the travelers reported having sought pretravel consultation; similar rates were found in other studies [7-13]. VFRs pursued less often health information than those traveling for leisure or for work. Inadequate pretravel preparation, visiting rural areas, traveling for longer periods of time, and staying with local people in developing countries predispose VFRs, compared with other travelers, to many largely preventable infectious diseases [3-6, 20].

Vaccination rate in the current survey was low; however it was comparable with the results of other studies $[8,10-$ 12]. Hepatitis A vaccine was the prevalent vaccine delivered. 
TABLE 4: Travelers and travel characteristics by purpose of travel.

\begin{tabular}{|c|c|c|c|c|}
\hline & Tourists & Business travelers & VFRs & $P$ value \\
\hline Age & & & & $<0.001$ \\
\hline $19-34$ & $39(54.2)$ & $24(16.8)$ & $39(28.5)$ & \\
\hline $35-49$ & $25(34.7)$ & $103(72)$ & $83(60.6)$ & \\
\hline $50-64$ & $8(11.1)$ & $13(9.1)$ & $12(8.8)$ & \\
\hline$\geq 65$ & $0(0)$ & $3(2.1)$ & $3(2.2)$ & \\
\hline Gender & & & & $<0.001$ \\
\hline Male & $25(34.7)$ & $126(88.1)$ & $90(65.7)$ & \\
\hline \multicolumn{5}{|l|}{ Nationality } \\
\hline Greek & $69(95.8)$ & $140(97.9)$ & $13(9.5) *$ & $<0.001$ \\
\hline Other & $3(4.2)$ & $3(2.1)$ & $124(90.5)$ & \\
\hline \multicolumn{5}{|l|}{ Education } \\
\hline University/tertiary & $63(87.5)$ & $132(92.3)$ & $32(24.6)$ & $<0.001$ \\
\hline Secondary school & $7(9.7)$ & $7(4.9)$ & $37(28.5)$ & \\
\hline Elementary school & $2(2.8)$ & $4(2.8)$ & $61(46.9)$ & \\
\hline Employment & & & & $<0.001$ \\
\hline Yes & $69(95.8)$ & $142(100)$ & $96(70.1)$ & \\
\hline Duration of travel & & & & $<0.001$ \\
\hline$<$ month & $68(94.4)$ & $44(30.8)$ & $21(15.3)$ & \\
\hline $1-3$ months & $2(2.8)$ & $37(25.9)$ & $75(54.7)$ & \\
\hline $3-6$ months & $2(2.8)$ & $20(14)$ & $27(19.7)$ & \\
\hline$>6$ months & $0(0)$ & $42(29.4)$ & $14(10.2)$ & \\
\hline Destination & & & & $<0.001$ \\
\hline North Africa & $22(30.6)$ & $25(17.5)$ & $77(56.2)$ & \\
\hline Sub-Saharan Africa & $44(61.1)$ & $111(77.6)$ & $55(40.2)$ & \\
\hline South Africa & $6(8.3)$ & $7(4.9)$ & $5(3.7)$ & \\
\hline Place of stay & & & & $<0.001$ \\
\hline Hotel & $68(94.4)$ & $44(30.8)$ & $1(0.7)$ & \\
\hline House & $1(1.4)$ & $87(60.8)$ & $136(99.3)$ & \\
\hline Camping & $3(4.2)$ & $3(2.1)$ & $0(0)$ & \\
\hline Ship & $0(0)$ & $9(6.3)$ & $0(0)$ & \\
\hline Area of stay & & & & $<0.001$ \\
\hline Urban & $64(88.9)$ & $112(80)$ & $52(38)$ & \\
\hline Urban + rural & $6(8.3)$ & $21(15)$ & $59(43.1)$ & \\
\hline Rural & $2(2.8)$ & $7(5)$ & $26(19)$ & \\
\hline
\end{tabular}

* People of African origin with Greek citizenship.

Similarly, this was the most common vaccine administered in similar studies $[8,10-12]$. Although more than $90 \%$ of travelers visited areas endemic for hepatitis $\mathrm{A}$, vaccination rate for hepatitis A was lower than expected as shown by retrospective analysis of travel and travelers' characteristics. A possible reason may be previous vaccination as part of the National Immunization Program of Greece or previous travel to tropical or subtropical countries. However, lack of knowledge about risk destinations may be another reason $[21,22]$.

Typhoid vaccine was delivered to $17.5 \%$ of travelers; this rate was lower compared to the results of other studies $[8,12]$. Nearly $80 \%$ of all travelers visited typhoid fever endemic countries. Although VFRs accounted for more than one-third of the travelers and more than $80 \%$ of them stayed for $\geq 1$ month and nearly all of them at local houses, only a few of them $(<2 \%)$ received typhoid fever vaccine; this may be the result of inadequate pretravel health seeking practices of VFRs as shown by a previous Greek study [20]. Retrospective analysis based on travel and travelers' characteristics showed that the vaccination rate against typhoid fever was lower than expected (55\%).

Meningococcal vaccine was administered to those traveling to sub-Saharan Africa. Nearly two-thirds of the travelers to sub-Saharan Africa intended to stay for long period of time and for work; as shown by retrospective analysis of data this rate was lower by $25 \%$. Meningococcal vaccination should be considered in "all travelers to countries in the sub-Saharan meningitis belt" in particular for those traveling during the dry season or those staying in the area for longer periods and living with or being in close contact with the local population for whom the risk of infection may be greater [23, 24]. Yellow 
TABLE 5: Multivariate analysis of factors associated with not pursuing health information among travelers to African countries.

\begin{tabular}{lcc}
\hline Characteristics & OR $(95 \%$ CI $)$ & $P$ value \\
\hline Education level & $10.2(3.58-29.22)$ & $<0.001$ \\
$\quad$ Elementary school & $4.89(2.10-11.42)$ & $<0.001$ \\
$\quad$ Secondary school & & \\
$\begin{array}{l}\text { Purpose of travel } \\
\quad \text { VFRs (visiting friends and relatives) }\end{array}$ & $5.23(2.46-11.11)$ & $<0.001$ \\
$\begin{array}{l}\text { Duration of travel } \\
\quad<1 \text { month }\end{array}$ & $3.97(2.05-7.67)$ & $<0.001$ \\
$\begin{array}{l}\text { Traveling with someone } \\
\text { Friends and relatives }\end{array}$ & $2.66(1.20-5.88)$ & 0.016 \\
$\begin{array}{l}\text { Previous travel } \\
\quad \text { Yes }\end{array}$ & $2.86(1.49-5.48)$ & 0.002 \\
\hline
\end{tabular}

fever vaccine was administered only to travelers visiting subSaharan Africa (47.9\%); lower vaccination rate was justified due to previous immunity as shown by retrospective analysis.

Rabies vaccine was administered to only $1.9 \%$ of all travelers and only to travelers visiting sub-Saharan Africa (3.3\%). Only $0.1 \%$ of travelers VFRs and $0.6 \%$ of long-term travelers were vaccinated against rabies despite traveling to a rabiesendemic country. Travelers' and travel health providers' lack of knowledge about the risks of rabies exposure may be related to the low vaccination rates against rabies, as shown in recent studies $[25,26]$; results from a previous Greek survey showed that travel health consultants' knowledge regarding preexposure rabies prophylaxis was deficient [25].

In the current study, vaccination with routine vaccines such as tetanus/diphtheria was comparable to the rates of another study [10]. Previous vaccination coverage through the National Vaccination Program of Greece which is provided by health professionals other than travel health consultants may be responsible for low vaccination rates with routine vaccines [27]. Since influenza is considered as the most common travel-associated, vaccine-preventable infectious disease it is important to increase travelers' awareness of influenza risk distribution and prevention measures [28]. Furthermore specific recommendations are needed which address the indications for influenza vaccination in travelers [29].

Malaria risk was assessed according to destination countries, area and place of stay, purpose, and duration of travel. The rate of malaria chemoprophylaxis in the current study was comparable to the rate in other studies [8-10, $12,30]$. None of the travelers was prescribed SBET (Stand By Emergency Treatment). Retrospective analysis of data based on travel and travelers' showed that approximately $22 \%$ of all travelers who visited malaria endemic areas did not receive any antimalarials. Only $6.6 \%$ of VFRs and $67 \%$ of business travelers who traveled to malaria endemic areas were prescribed chemoprophylaxis, whereas approximately $8 \%$ of business travelers who traveled for more than six months to malaria endemic areas had no information about SBET; for travelers visiting high risk areas and staying in remote locations for prolonged period of time SBET is indicated
[15]. These results suggest that malaria prophylaxis was inadequate, in particular with regard to special groups, such as VFRs and business travelers which may be related to their lack awareness about the risk of the disease $[22,30]$.

\section{Conclusions}

Travel medicine providers were underutilized with only one half of all travelers to African destinations reporting having sought pretravel consultation. Inadequate vaccination coverage and malaria prevention of travelers to high risk destinations suggest that public health strategies should be developed in order to increase travelers' awareness about the risk of exposure to travel-related infectious diseases and the importance of pretravel consultation. In particular, there is a special need for education initiatives to target high risk groups of travelers such as travelers VFRs and business travelers. Travel health providers should increase their efforts through training and continuing professional development in order to propagate safe and healthy travel.

\section{Ethical Approval}

Approval to contact the study was provided by the Athens International Airport Authority, the involved airlines, and the Hellenic Center for Disease Control and Prevention (Athens, Greece).

\section{Conflict of Interests}

The authors state they have no conflict of interests to declare.

\section{Acknowledgments}

The authors appreciate the support of the Airport Operator and the Hellenic Civil Aviation Authority. They are indebted to all travelers who participated in the survey and thank all individual airlines for their assistance and cooperation.

\section{References}

[1] World Tourism Organization, "Tourism 2020 vision," 2013, http://www.world-tourism.org/.

[2] K. Khan, J. Arino, W. Hu et al., "Spread of a novel influenza A (H1N1) virus via global airline transportation," New England Journal of Medicine, vol. 361, no. 2, pp. 212-214, 2009.

[3] D. O. Freedman, L. H. Weld, P. E. Kozarsky et al., "Spectrum of disease and relation to place of exposure among ill returned travelers," New England Journal of Medicine, vol. 354, no. 2, pp. 119-130, 2006.

[4] K. Leder, J. Torresi, M. D. Libman et al., "GeoSentinel surveillance network. GeoSentinel surveillance of illness in returned travelers, 200-2011," Annals of Internal Medicine, vol. 158, no. 6, pp. 456-468, 2013.

[5] A. K. Boggild, F. Castelli, P. Gautret et al., "Vaccine preventable diseases in returned international travelers: results from the GeoSentinel Surveillance Network," Vaccine, vol. 28, no. 46, pp. 7389-7395, 2010. 
[6] K. Leder, J. Black, D. O’Brien et al., "Malaria in travelers: a review of the GeoSentinel surveillance network," Clinical Infectious Diseases, vol. 39, no. 8, pp. 1104-1112, 2004.

[7] K. Van Herck, J. Zuckerman, F. Castelli, P. Van Damme, E. Walker, and R. Steffen, "Travelers' knowledge, attitudes, and practices on prevention of infectious diseases: results from a pilot study," Journal of Travel Medicine, vol. 10, no. 2, pp. 75-78, 2003.

[8] R. Lopez-Velez and J. Bayas, "Spanish travelers to high-risk areas in the tropics: airport survey of travel health knowledge, attitudes, and practices in vaccination and malaria prevention," Journal of Travel Medicine, vol. 14, no. 5, pp. 297-305, 2007.

[9] G. Ropers, M. Du Ry van Beest Holle, O. Wichmann et al., "Determinants of malaria prophylaxis among German travelers to Kenya, Senegal, and Thailand," Journal of Travel Medicine, vol. 15, no. 3, pp. 162-171, 2008.

[10] R. C. Larocque, S. R. Rao, A. Tsibris et al., "Pre-travel health advice-seeking behavior among US International travelers Departing from Boston Logan International Airport," Journal of Travel Medicine, vol. 17, no. 6, pp. 387-391, 2010.

[11] A. E. Heywood, R. E. Watkins, S. Iamsirithaworn, K. Nilvarangkul, and C. R. MacIntyre, "A cross-sectional study of pre-travel health-seeking practices among travelers departing Sydney and Bangkok airports," BMC Public Health, vol. 12, p. 321, 2012.

[12] A. Wilder-Smith, N. S. Khairullah, J. Song, C. Chen, and J. Torresi, "Travel health knowledge, attitudes and practices among Australasian travelers," Journal of Travel Medicine, vol. 11, no. 1, pp. 9-15, 2004.

[13] P. Gautret, P. Schlagenhauf, J. Gaudart et al., "Multicenter EuroTravNet/GeoSentinel study of travel-related infectious diseases in Europe," Emerging Infectious Diseases, vol. 15, no. 11, pp. 17831790, 2009.

[14] Hellenic Centre for Disease Control and Prevention, 2013, http://www.keelpno.gr/.

[15] World Health Organization, International Travel and Health, 2013, http://www.who.int/ith/en/index.html.

[16] Centers for Disease Control and Prevention, 2013, http:// wwwnc.cdc.gov/travel/.

[17] Centers for Disease Control and Prevention, CDC Health InFormation for International Travel 2010, U.S. Department of Health and Human Services, Public Health Service, Atlanta, Ga, USA, 2009.

[18] Hellenic Statistical Authority, 2013, http://www.statistics.gr/ portal/page/portal/ESYE.

[19] A. Pavli, A. Spilioti, I. Lymperi et al., "Vaccinations for international travellers travelling from Greece," Travel Medicine and Infectious Disease, vol. 11, no. 4, pp. 225-230, 2013.

[20] A. Pavli, P. Katerelos, I. N. Pierroutsakos, and H. C. Maltezou, "Pre-travel counselling in Greece for travellers visiting friends and relatives," Travel Medicine and Infectious Disease, vol. 7, no. 5, pp. 312-315, 2009.

[21] National School of Public Health, National vaccination Coverage Report 2006, http://www.nsph.gr/files/011_Ygeias_Paidiou/ Ereunes/emvolia_tblimoxi_2006_ekthesi.pdf.

[22] P. J. J. van Genderen, P. P. A. M. van Thiel, P. G. H. Mulder, and D. Overbosch, "Trends in knowledge, attitudes, and practices of travel risk groups toward prevention of hepatitis A: results from the Dutch Schiphol Airport Survey 2002 to 2009," Journal of Travel Medicine, vol. 19, no. 1, pp. 35-43, 2012.
[23] R. Steffen, "The risk of meningococcal disease in travelers and current recommendations for prevention," Journal of Travel Medicine, vol. 17, no. 1, pp. 9-17, 2010.

[24] World Health Organization, International travel and health, 2013, http://www.who.int/ith/chapters/ith2012en_chap6.pdf .

[25] A. Pavli, G. Saroglou, S. Hadjianastasiou et al., "Knowledge and practices about rabies among travel medicine consultants in Greece," Travel Medicine and Infectious Disease, vol. 9, no. 1, pp. 32-36, 2011.

[26] M. Altmann, P. Parola, J. Delmont, P. Brouqui, and P. Gautret, "Knowledge, attitudes, and practices of french travelers from marseille regarding rabies risk and prevention," Journal of Travel Medicine, vol. 16, no. 2, pp. 107-111, 2009.

[27] National Vaccination Program for Children and Adolescents, 2011, http://www.scribd.com/doc/98387000/B1\%CF\%83\%CE\% BC\%CE\%BF\%CF\%8D-2011.

[28] R. Steffen, "Influenza in travelers: epidemiology, risk, prevention, and control issues," Current Infectious Disease Reports, vol. 12, no. 3, pp. 181-155, 2010.

[29] S. Helfenberger, A. Tschopp, L. Robyn, C. Hatz, and P. Schlagenhauf, "Knowledge, attitudes, and practices of business travelers regarding influenza and the use of antiviral medication," Journal of Travel Medicine, vol. 17, no. 6, pp. 367-373, 2010.

[30] P. J. van Genderen, P. P. van Thiel, P. G. Mulder, and D. Overbosch, "Trends in the knowledge, attitudes and practices of travel risk groups towards prevention of malaria: results from the Dutch Schiphol Airport Survey 2002 to 2009," Malaria Journal, vol. 11, p. 179, 2012. 


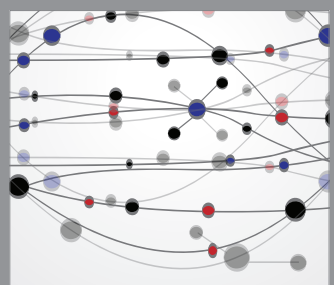

The Scientific World Journal
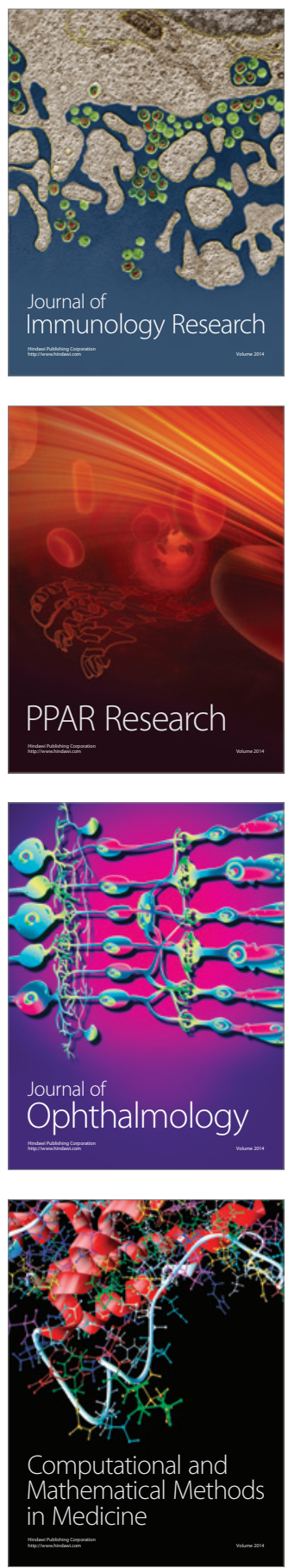

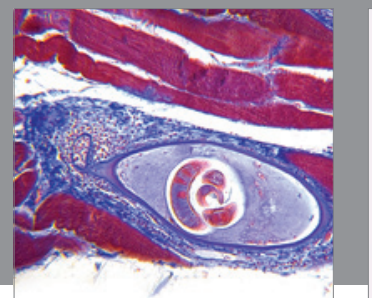

Gastroenterology

Research and Practice
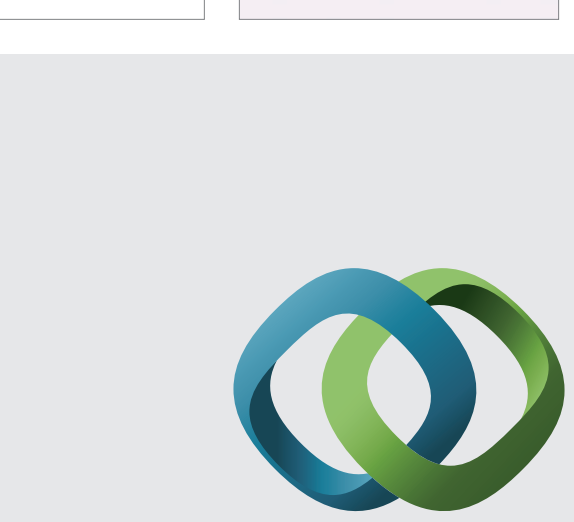

\section{Hindawi}

Submit your manuscripts at

http://www.hindawi.com
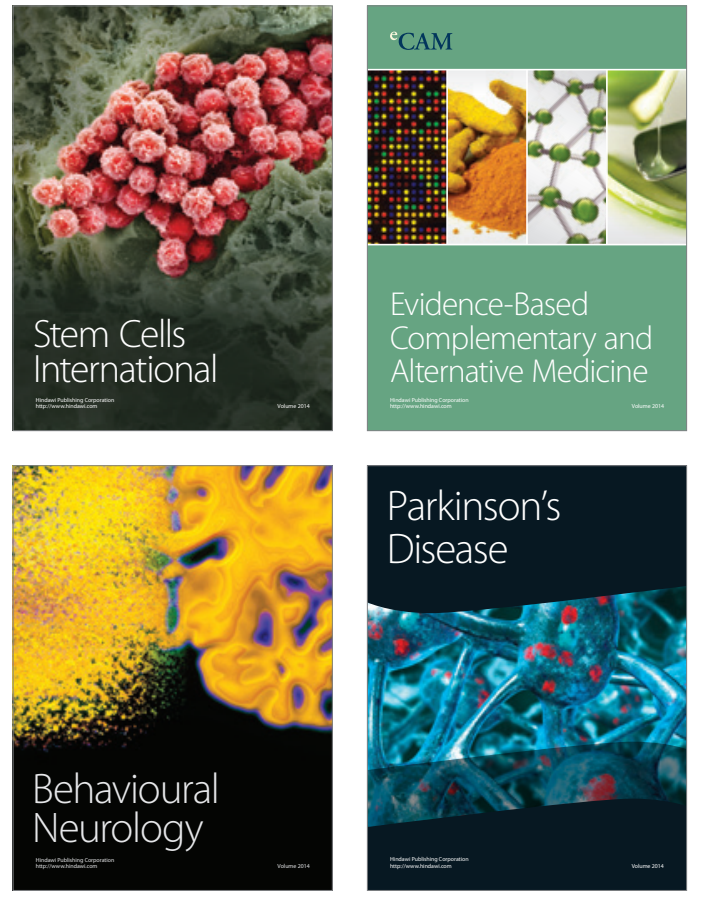
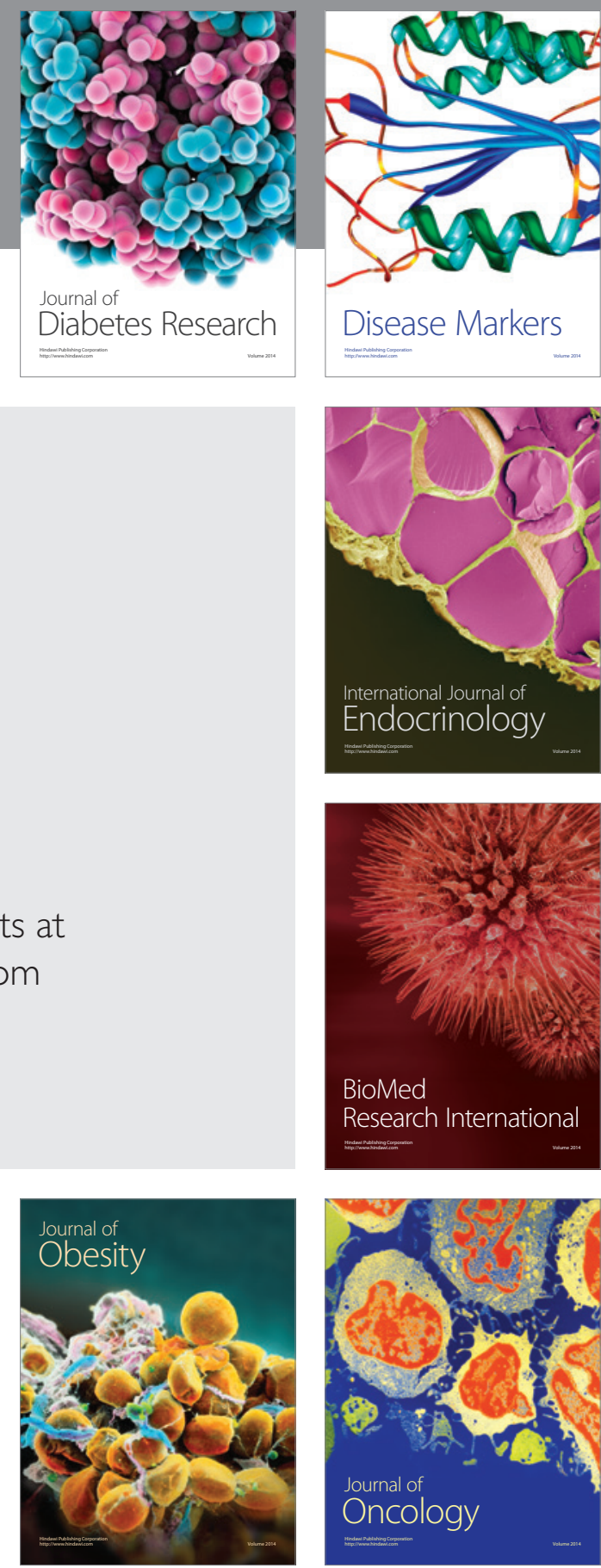

Disease Markers
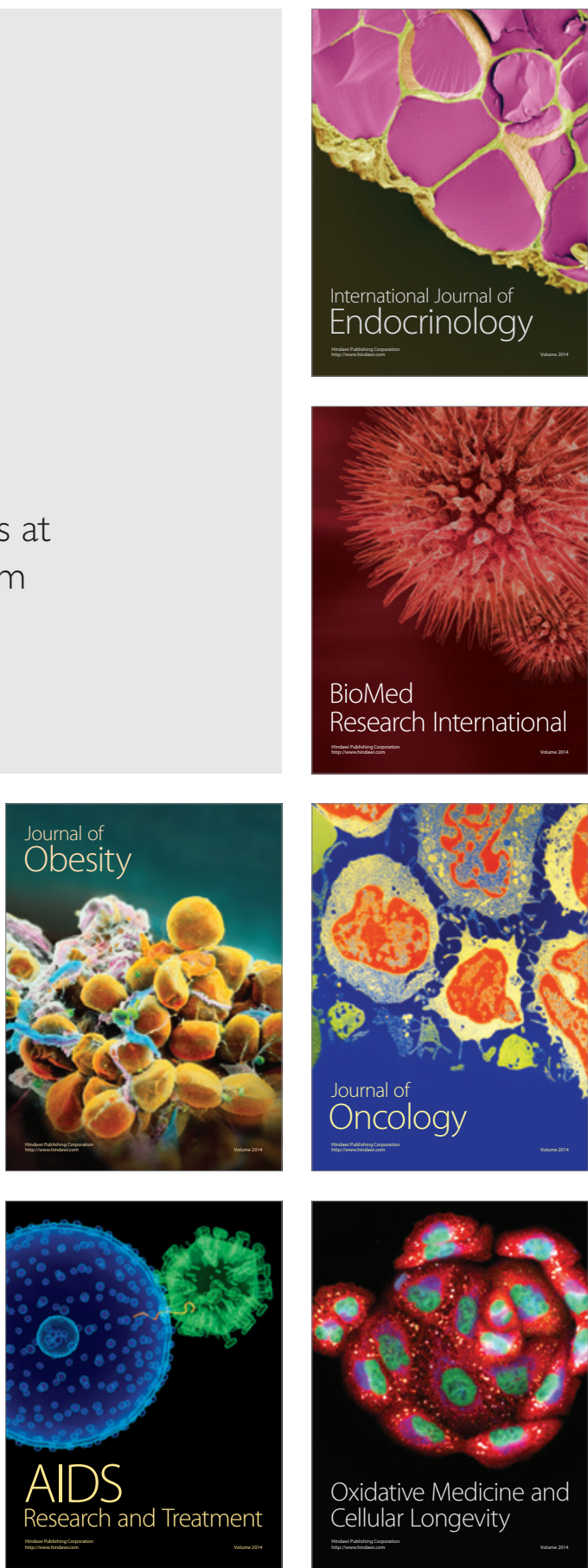